Transliteration of both Russian and Buryat examples in this book follows a modified version of the American Library Association-Library of Congress (ALA-LC) system for Cyrillic, except for terms that already have established English spellings (e.g., Buryat, Ulan-Ude, etc.), and for ease of pronunciation with recurring personal names (e.g., Sayana). The ALA-LC system was originally developed for Slavic languages, and the pronunciation of some characters in Mongolic languages differs, but not in ways that bear on the text. To transliterate the three "extra" letters of the Buryat alphabet, I follow the standard in Mongolian linguistics (Kara 1996, 557): $\Theta \Theta[\ddot{0}]$ appears as $O \ddot{o}, Y_{Y}[\ddot{\mathrm{u}}]$ as $\ddot{U} \ddot{u}$, and $h h[\mathrm{~h}]$ as Hh. Spelling is based on the Cyrillic of standard orthography, except in those instances in which pronunciation deviates from standard spelling in a way that is socially meaningful for the example at hand.

Russian appears in italics and Buryat with underlining; when something is both italicized and underlined, it indicates that the form could be considered both Russian and Buryat in context. Periodic references to Mongolian are also underlined. In transcriptions, boldface indicates emphasis, and (.) and (..) mark pauses. I follow standard practice in linguistics in reserving single quotation marks for glosses and using double quotation marks elsewhere. Material quoted from audio recordings, print sources, or in situ notes is marked with double quotation marks; paraphrases and quotations that have been reconstructed based on scratch notes and memory do not appear in quotation marks. Most of the informal interactions described in this book were not digitally recorded, while nearly all of the interviews and focus groups were. Place names that do not already have common English-language versions are given in Buryat wherever possible, with one exception: when discussing dialects, I use Russian adjectives over Buryat (e.g., "Khorinskii dialect" rather than "Khori"), consistent with the way Buryat speakers most often identify dialects and dialectal forms. All translations are mine. 



\section{MIXED MESSAGES}


